\title{
MANAGEMENT OF ACUTE PSYCHOSIS IN LEPROMATOUS LEPROSY
}

\author{
hy R. H. Thanga RaJ, M.B.B.S. \\ and Mrs. Sarojini Thanga Raj, m.B.b.S. \\ Purulia Leprosy Home and Hospital, \\ Purulia, West Bengal
}

Acute psychosis in lepromatous leprosy is not very common now but still we get a few cases now and then. If not properly treated they go into the chronic stage which is rather a difficult problem for doctors working in leprosy homes.

The symptoms and signs vary according to the severity of the case. This article is based on five cases treated during the course of two years. Four of the five patients were receiving the sulphones at the onset of the symptoms and in one treatment was discontinued because of repeated reactions. In most of the cases some tragic incident in the domestic side precipitated the attack. In three out of the five cases we were able to trace the cause to the family. In one infection may have played a part as the patient had a very bad ulcer. One or two days before the onset of the acute stage the patient becomes non-cooperative, tends to be unruly and abusive. There may be a slight rise in pulse rate and temperature. Careful and patient management at this stage is required. Scolding the patient and trying to discharge him from the ward will only aggravate the condition. The next stage is the acute stage when the patient looks very anxious and confused. There is flight of ideas and thinking is retarded. Sleep is disturbed and the patient becomes violent and angry if not properly managed. He abuses each and everyone and feels he is being persecuted by all. He refuses to take food and water. In four of the five cases there was high temperature and erythema nodosum or subcutaneous nodules.

There are four essential things one has to consider in the management of these cases. They are (1) Isolation; (2) Sedation; (3) Maintainance of fluid and vitamin levels in the body, and (4) Occupational therapy when once the acute stage is passed. In this article only the first three are dealt with.

Isolation in our opinion is absolutely necessary for two reasons. The patient gets excited on seeing people around him and the other reason is that the fellow-patients acting as nurses who help in the wards make fun of the patient without realizing the condition of the patient. He should be assigned nurses who have understanding of the mental condition of the patient.

Sedation was best achieved in all the cases by the parenteral administration of Chlorpromazine (Largactil). We have also tried paraldehyde in combination with barbiturates in previous cases but Largactil has proved to be far superior. Of course this report is based 
only on five cases. The parenteral dosage administered was $75 \mathrm{mg}$. of Largactil four hourly on the first day and then $50 \mathrm{mg}$. four hourly from the second day onwards. The intervals of administration were lengthened as the symptoms subsided. The symptoms subsided in all the cases from three to six days.

Fluid level at all costs should be maintained. In three cases we administered 2-3 pints of intravenous saline in each case as they persistently refused to take anything. Five to six pints of fluid by mouth should be sufficient. The vitamin level was maintained by giving $200 \mathrm{mg}$. of vitamin C and 2 cc. of vitamin B complex daily intramuscularly. All the patients recovered from the acute attack.

In one case high doses of penicillin was administered along with Largactil and vitamins as we suspected infection may have played a part.

\section{Summary}

1. This article is based on five cases.

2. Some of the symptoms and signs are described above.

3. The four essential things in the mangement of acute psychosis are:

(a) Isolation.

(b) Sedation.

(c) Maintainance of fluid and vitamin levels.

(d) Occupational therapy.

4. Sedation is best achieved by parenteral administration of Largactil. 